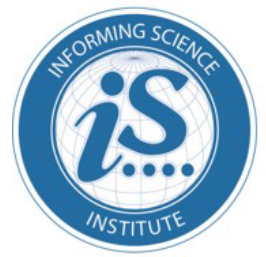

Interdisciplinary Journal of E-Skills and Lifelong Learning

Volume 14, 2018

An Official Publication

of the Informing Science Institute

InformingScience.org

\title{
IJELL.org
}

\section{1st Century SkILls: Student Perception OF ONLINE INSTRUCTOR ROLE}

Asmaa Ganayem*

Wafa Zidan

*Corresponding author
Al-Qasemi college of Education and MOFET Institute, Tel Aviv, Israel

The Arab Academic College for Education in Israel, Haifa and MOFET Institute, Tel Aviv, Israel dr.asmaag@gmail.com

wafazidan@arabcol.ac.il

AbSTRACT

Aim/Purpose

This research inquires how students perceive the role of Technology Education and Cultural diversity (TEC) instructors in improving their $21^{\text {st }}$ century skills. In addition, this study examines the students' preferred learning style: face to face, synchronous and asynchronous.

Background

$21^{\text {st }}$ century skills include, among others, collaboration, Information and Communication Technology (ICT) skills, higher order thinking, and multicultural communication. These skills are core elements for modern life and are the focus of this study as teacher critical career and life skills. This article presents the uniqueness of the TEC model, which provides a strategy to develop gradually various $21^{\text {st }}$ century skills for teacher training in a multicultural technologically rich environment.

Methodology This study examined (a) the level of ICT skills students acquire from the courses; (b) students' perceptions of the instructor role in developing $21^{\text {st }}$ century skills; and (c) students' preferred learning style. A questionnaire was delivered to 99 students, who participated in courses based on the TEC model. Students from eight different Teacher Education Colleges and different cultural backgrounds - Arabs, Jews, religious, and secular - participated in this study.

Contribution

This study could shed light on the instructor's role as a facilitator in developing students' $21^{\text {st }}$ century skills in a multicultural society. This study may provide a model and ideas for policy makers in teacher training programs to employ $21^{\text {st }}$ century skills along with continuous development and adaptation to suit the rapid changing reality. A larger study needed to examine additional aspects of the $21^{\text {st }}$ century skills in the teacher training programs in general and in multicultural societies in particular.

Accepted by Editor Nicole Buzzetto-Hollywood | Received: April 1, 2018 | Revised: June 22, July 8, 2018 Accepted: July 9, 2018.

Cite as: Ganayem, A., \& Zidan, W. (2018). 21st century skills: Students' perception of online instructor role. https:/ / doi.org/ 10.28945/4090, 14, 117-141. https://doi.org/10.28945/4090

(CC BY-NC 4.0) This article is licensed to you under a Creative Commons Attribution-NonCommercial 4.0 International License. When you copy and redistribute this paper in full or in part, you need to provide proper attribution to it to ensure that others can later locate this work (and to ensure that others do not accuse you of plagiarism). You may (and we encourage you to) adapt, remix, transform, and build upon the material for any non-commercial purposes. This license does not permit you to use this material for commercial purposes. 
Findings

Recommendations for Practitioners

Recommendations for Researchers

Impact on Society

Future Research

Keywords
The findings show that students complete the course with a high level of ICT skills, and that their preferred learning communication style was face-to-face (F2F) $(45.45 \%)$ and blended method (43.43\%), over the fully online $(11.11 \%)$. Regarding online learning, students mostly preferred the mixed method of synchronous and asynchronous (59\%), followed by asynchronous $(29 \%)$, and synchronous $(12 \%)$. As to student preference of the instructor role of enhancement, the results were prioritized as follow: Higher order thinking $(\mathrm{M}=3.99)$, online group collaboration $(\mathrm{M}=3.87)$, multicultural communication awareness $(\mathrm{M}=3.82)$, pedagogical use of digital tools $(\mathrm{M}=3.73)$.

Teacher education lecturers ought to: (1) design the online courses in a way that integrates F2F meetings and both synchronous and asynchronous methods; and (2) employ the wide range of skills in TEC courses that comply with 21 st century principles; hence, the importance of widening such courses in teacher education colleges.

It is recommended to perform a similar study using a pre-post method, as well as taking into consideration cultural uniqueness (such as language differences) and group comparison, where we can identify the effective components of the course design that would lead to a higher level of $21^{\text {st }}$ century skills competencies among teachers.

$21^{\text {st }}$ century skills are life skills, hence developing these skills in an appropriate educational setting reflects better utilization among all the members of society.

More research should be done to widen the knowledge and address the importance of the instructor role as a course designer and facilitator in order to turn $21^{\text {st }}$ century learning into a more meaningful and relevant one.

$21^{\text {st }}$ century skills, online collaborative learning, course design, instructor role, TEC model

\section{INTRODUCTION}

Learning theories emerged in the $20^{\text {th }}$ century, with three major theoretical frameworks shaping the study of learning (Harasim, 2017).

The Israeli Ministry of Education (2011) adopted collaboration as a constructivist learning pedagogy. Implementing this pedagogy in a technological framework made "online collaboration" an innovative learning experience desired by modern educational policies. $21^{\text {st }}$ century skills comprise the skills needed to manage our lives effectively within a complex reality and an interconnected world. Collaboration, cooperation, teamwork, and effective communication, are all core elements in $21^{\text {st }}$ century skills (P21 Partnership for 21 ${ }^{\text {st }}$ Century Learning, 2015).

It is the responsibility of education to provide students with these critical skills for the challenge of a continuously changing digital world in a multicultural diverse society.

Modern societies are characterized by the mobility and immigration of people across different countries, while social exclusion of minorities and culturally diverse communities still occur in the public sphere (Babacan, 2005). Stereotypes exist between communities, and are reflected in discriminations and tensions in everyday life. Hence various educational and social inclusion programs should be implemented in order to build a better diverse world, especially in our digitally connected communities.

This study was held in the Israeli teacher training system. Israeli society is divided by continuous tension between different cultures and religions (Ghanem, 2001). This division is directly reflected in the educational system, mainly in the separation into three school and college subsystems: secular Jewish, religious Jewish and the Arab sector. Arab students constitute about 27\% of the Israeli educational 
system, the religious Jewish sector constitutes about 30\%, and $43 \%$ belongs to the general/secular Jewish education system (Viceblai, 2013).

This division maintains stigmas and ignorance between students, and meeting or collaborating between the different cultures is rare because of many logistical and psychological barriers. This is a critical challenge in the $21^{\text {st }}$ century, since technology is highly used in Israel and communication channels are available, while students do not have the appropriate skills for collaboration in a multicultural environment. Hence, the importance of Technology, Education and Cultural diversity (TEC) programs, in which students from different colleges - Arab/Jews, secular/religious - learn online collaboratively in a systematic gradual model (Hoter, Shonfeld, \& Ganayem, 2009; Shonfeld, Hoter, \& Ganayem, 2013).

The instructors (lecturers and teachers) of TEC courses are also from different cultures and colleges. Those programs aim to develop collaborative skills among culturally diverse students which will help in reducing stigmas (Walther, Hoter, Ganayem, \& Shonfeld, 2015). The technology of the $21^{\text {st }}$ century enables us to overcome the logistical and psychological barriers of face to face meetings and also promotes trust building between people of diverse backgrounds (Walther \& Bunz, 2005; AmichaiHamburger, 2012). The TEC model adopts different $21^{\text {st }}$ century skills, with instructors acting as a role model for the students by the methods they use to integrate technology and to collaborate in their work. The TEC model also adopts these skills in the instructional design of the courses, as well as in their contents and assignments.

The students in college courses work collaboratively in small multicultural groups of six members to solve tasks. An online forum, along with other Computer Mediated Communication (CMC) environments, are available to students through the Learning Management System (LMS). Successful online collaboration is an important learning target as well as a social one (Walther \& Bunz, 2005; Amichai-Hamburger, 2012). The role of the instructors is critical in designing, facilitating and supporting the students for a successful learning process (Harasim, 2017).

This study examines the ICT skills acquired by students and developed throughout the course, their online learning style preferences, and their perceptions of the instructor role in developing various $21^{\text {st }}$ century skills such as online group collaboration, higher order thinking skills (HOTS), pedagogical use of tools and multicultural awareness. This study can shed light on the future design of online courses that aim among other things to develop students' $21^{\text {st }}$ century skills and multicultural awareness.

The following presents a literature review concerning $21^{\text {st }}$ century skills, online collaborative learning, online learning styles, instructor role and the TEC model.

\section{LITERATURE REVIEW}

\section{$2 P^{T}$ CENTURY SKILLS}

The current century is known as the Knowledge Age in which knowledge has key social, economic value, political and media power. The widespread phenomena of new digital environments and mobile technologies led to the creation of new theories and models in education, mainly connectivism and collaborativism, to address the needs and opportunities of the $21^{\text {st }}$ century (Harasim, 2017).

Many suggestions exist nowadays for a set of skills needed for a successful life in the $21^{\text {st }}$ century. The P21 (P21 Partnership for 21 ${ }^{\text {st }}$ Century Learning, 2015) developed a framework that describes the knowledge, skills, and expertise that students must master to succeed in work and life. This framework categorized the $21^{\text {st }}$ century skills into the following categories, which is also adapted in the Israeli educational system: 
- Key subjects and $21^{\text {st }}$ century themes: (1) formal subjects, such as languages, math and others; and (2) interdisciplinary subjects, such as finance, global health literacy in a higher level of awareness and understanding.

- Learning and innovation skills: this category includes skills that prepare students for a complex life, and includes critical thinking and problem solving, creativity and innovation, communication and collaboration.

- Information, media and technology skills: information, media, ICT, literacy; accessing, analyzing, creating, and applying.

- Life and career skills: skills needed to meet the challenges of modern life such as flexibility, cross-cultural skills, leadership, etc.

Jacobson-Lundeberg (2016) showed how teaching $21^{\text {st }}$ century skills modified the lives of college student and empowered them, despite the fact that those students came from a marginalized socioeconomic community. Andrade (2016) showed how using ICT integrated pedagogy (flipped classroom) enhanced $21^{\text {st }}$ century skills among students.

The study of teacher training in Israel shows that educators and mentors are still modeling traditional technology in education through presentation and demonstration use despite the fact that the Israeli Ministry of Education (2011) has adapted the $21^{\text {st }}$ century skills to its educational system (Goldstein \& Asaf, 2014; Goldstein \& Tesler, 2017).

Since ICT is part of our daily life, it is critical to integrate ICT in education side by side with the use of the special opportunities of ICT to develop other $21^{\text {st }}$ century skills. Multicultural communication and cooperation is much more possible in a rich ICT environment. TEC courses not only teach ICT skills in education, its instructional design model uses various pedagogical models and teaching strategies such as flipped classroom, synchronous and asynchronous strategies, to convey modeling to the learners.

\section{ONLINE COLLABORATIVE LEARNING}

Collaborativism theory Online Collaborative Learning (OCL) addresses the needs and opportunities of the knowledge age within a process of social interaction (Harasim, 2017). Online collaboration learning proposes to be joint student work in the same activity or assignment, which can be in the range of the different collaboration levels proposed by Salmon (2012).

Learning as a process of knowledge construction always has a social component. As described by Harasim (2017) "OCL theory provides a model of learning in which students are encouraged and supported to work together to create knowledge: to invent, to explore ways to innovate, and, by doing so, to seek the conceptual knowledge needed to solve problems rather than recite what they think is the right answer". The OCL theory encourages learners to be active and engage collaboratively in order to construct their knowledge. Discussion in the learning process seems to be essential and not supplemental or optional. Harasim (2017) proposes that resources should be chosen to support the discussion, and not the opposite. Concerning knowledge construction as the learning target, Harasim (2017) proposes three key phases: (a) idea generation (brainstorming); (b) idea organizing (comparing, analyzing etc.); and (c) intellectual convergence (synthesizing). This can be a framework for group work in learning tasks. In OCL classrooms, the teacher's role shifts from being that of a provider/entertainer to being more of a facilitator as students take on more responsibility for the learning process and for generating discourse (Harasim, 2017).

Since 2000, there has been a rapid growth in the institutions offering distance education courses and the number of students taking online courses, and this policy is supported and widened by most academic institutions (Allen \& Seaman, 2014). Online courses have a growing role in higher education; hence the special attention of this study and many other recent studies that try to examine instructional strategies toward enhancing learning outcomes. According to the Online Report Card (Online 
Learning Consortium, 2015), the number of students in the U.S. enrolled in at least one online course has increased from 10\% in 2002 to 30\% in 2010, and the attitude of Science, Mathematics and Computer Science instructors are more positive than Social Science and Art instructors toward online learning. Also in Israel, online collaboration is on the agenda of the Israeli education system, and has increased in online learning discourse (Israeli MOE, 2011).

Collaboration in education is an important factor for success. Digital development has enhanced and widened the ways in which collaboration can be made, and enabled collaboration to be implemented between geographically and culturally distanced people. Studies show that collaboration promotes and improves learning and is an important means for personal development (Barkley, Cross, \& Major, 2014). It is more and more recognized how collaboration promotes innovation and success in life.

Online collaboration is defined as being a critically required skill for life and work in our changing digital era. $21^{\text {st }}$ century skills, among other factors, provides collaboration, ICT skills, higher order thinking, and multicultural communication. These skills are core elements in Israeli $21^{\text {st }}$ century skills curricula (Israeli MOE, 2011). Collaborating effectively can develop interpersonal communication and ICT skills, which are essential for modern life and workplaces. Through innovative pedagogy and unique learning experiences, teachers should develop these skills. Faculty members are expected to design their online courses and assignments in a way that facilitates effective online collaboration.

Stephens and Roberts (2017) proposed four sequential phases, called the FCOG strategy for Facilitating Collaboration in Online Groups, in order to enhance student engagement. The strategy is composed of the following phases: (1) creating groups; (2) establishing expectations; (3) communication tools; and (4) assignments and activities.

Interpersonal student interaction is an important factor for student engagement (Faulkner, Doamekpor, \& Yeboah, 2013). Hence the importance of designing activities that enables appropriate online interpersonal communication. Stephens and Robert (2017) proposed three online group assignments that can enhance interpersonal communication within the group: (1) open assignments with no right answer (such as debate, information seeking etc.); (2) multiple perspectives on a topic (such as multicultural comparison, examining a subject from various point of views etc.; and (3) creating authentic products, in which they can integrate and apply their knowledge and skills.

The distance education context for this study is not independent learning but rather a context of collaborative, constructivist learning within a community of learners.

\section{ONLINE LEARNING STYLES}

The emergence of asynchronous and synchronous communications technology has made integrating different online learning styles possible such as distance learning, blended learning, and integration of synchronous and asynchronous learning styles.

A study comparing learner satisfaction and learning outcomes in online and face-to-face learning environments with similar format, found that students in the face-to-face course held slightly more positive perceptions about the instructor and overall course quality than the online course (Johnson, Aragon, Shaik, \& Palma-Rivas, 2000).

Ganayem and Daher (2006) found that student preference of the online courses learning method was based on five categories: Emotional aspect, effectiveness, interaction, course type, and the technological aspect. Students favored synchronous learning over asynchronous learning in the emotional aspect. Garrison, Anderson and Archer (2001), in their model "community of inquiry", emphasize three essential elements: Social presence, teaching presence, and cognitive presence. These elements enable the students to practice a unique and successful educational experience. Salmon (2012) also emphasized the instructors' presence in a successful online learning. Various studies proposed the 
importance of designing rich activities to enable appropriate interpersonal communication in online learning with the instructor and between students (Faulkner et al., 2013, Harasim, 2017).

\section{INSTRUCTOR ROLE}

Innovative pedagogical design and active involvement of the instructor is highlighted by various studies for successful online learning. Special focus is given in the literature concerning the critical role of the instructor in the success of OCL. Harasim (2017) sees the role not only as a facilitator of the resources and activities, but as a knowledge representative of the learned domain, ensuring student integration of the concepts, practices, standards and principles of the subject being studied:

In the OCL theory, the teacher plays a key role not as a fellow-learner, but as the link to the knowledge community, or state of the art in that discipline. Learning is defined as conceptual change and is a key to building knowledge. Learning activity needs to be informed and guided by the norms of the discipline and a discourse process that emphasizes conceptual learning and builds knowledge (Harasim, 2017).

Many studies in the past have found that online courses require significantly larger workloads, and report that instructors think teaching online was more difficult than teaching in-class. Hartman, Dziuban, and Moskal (2000) reported that $90 \%$ of the instructors surveyed in 32 online courses believe that online courses were more difficult to teach, and that they demand increased interactions with students.

Garrison et al. (2001) have developed the model of Community of Inquiry (CoI), which they defined as follows: "An educational community of inquiry is a group of individuals who collaboratively engage in purposeful critical discourse and reflection to construct personal meaning and confirm mutual understanding." The researchers proposed three essential elements of a community of inquiry:

- Social presence: the ability of participants to identify with the community in a trusting environment developing inter-personal relationships.

- Teaching presence: the design, facilitation, and direction of students toward personally meaningful and educationally worthwhile learning outcomes.

- Cognitive presence: the extent to which learners are able to construct their knowledge through sustained reflection and discourse.

Positive integration of all these elements enable students to have a unique and successful educational experience that can lead to deep academic learning, as well as the development of higher order thinking skills such as critical thinking, synthesis and evaluation.

Robert (2003), on the other hand, proposed six strategy dimensions of online teaching approaches, as a range of practices in the following dimensions:

1. Focus of use: presenting information to constructing knowledge.

2. Nature of use: informative to discursive.

3. Role of teacher: student self-learning to teacher actively present and involvement.

4. Time and place of use: a-synchronous use to synchronous based timetable.

5. Role of student: reactive to proactive.

6. Relationships with students: from no relationships to enable building relationships.

Researchers are still studying the elements leading to successful educational experiences in this dynamic digital world. Several studies show practical aspects that can be associated with successful online discussion such as appropriate technology, clear guidelines and expectations, student technological preparation, appropriate topics, instructor presence and assessment (Salmon, 2012; Garrison et al., 2001). In addition to these, Wach (2017) also includes the online intercultural experience and in her study, she indicates the critical role of intercultural online experience in broadening cultural knowledge and awareness. 
The instructor role in the knowledge age is still critical. The digital age shifted the instructor role from the classical role of information resource to a more complicated one, in which the instructor should master the $21^{\text {st }}$ century skills modeling the process and the outcomes that he or she are facilitating.

\section{TEC MODEL}

TEC model is a framework for designing effective online collaborative courses in a multicultural setting. The goal is to build bridges among learners from different cultures in a gradual collaborative method and to start by working collaboratively in small multicultural groups through effective use the Internet and other cutting-edge information technologies.

Trust building in learning groups should be gradual and should move through different stages of interaction and collaboration, starting from dialogue to peer review to parallel collaboration to sequential collaboration and finally to synergistic collaboration (Salmon, 2012; Hoter et al., 2009). Based on this perception, the TEC courses developed the tasks and utilized technology respectively, as will be presented in the following chart of the TEC model (Figure 1).

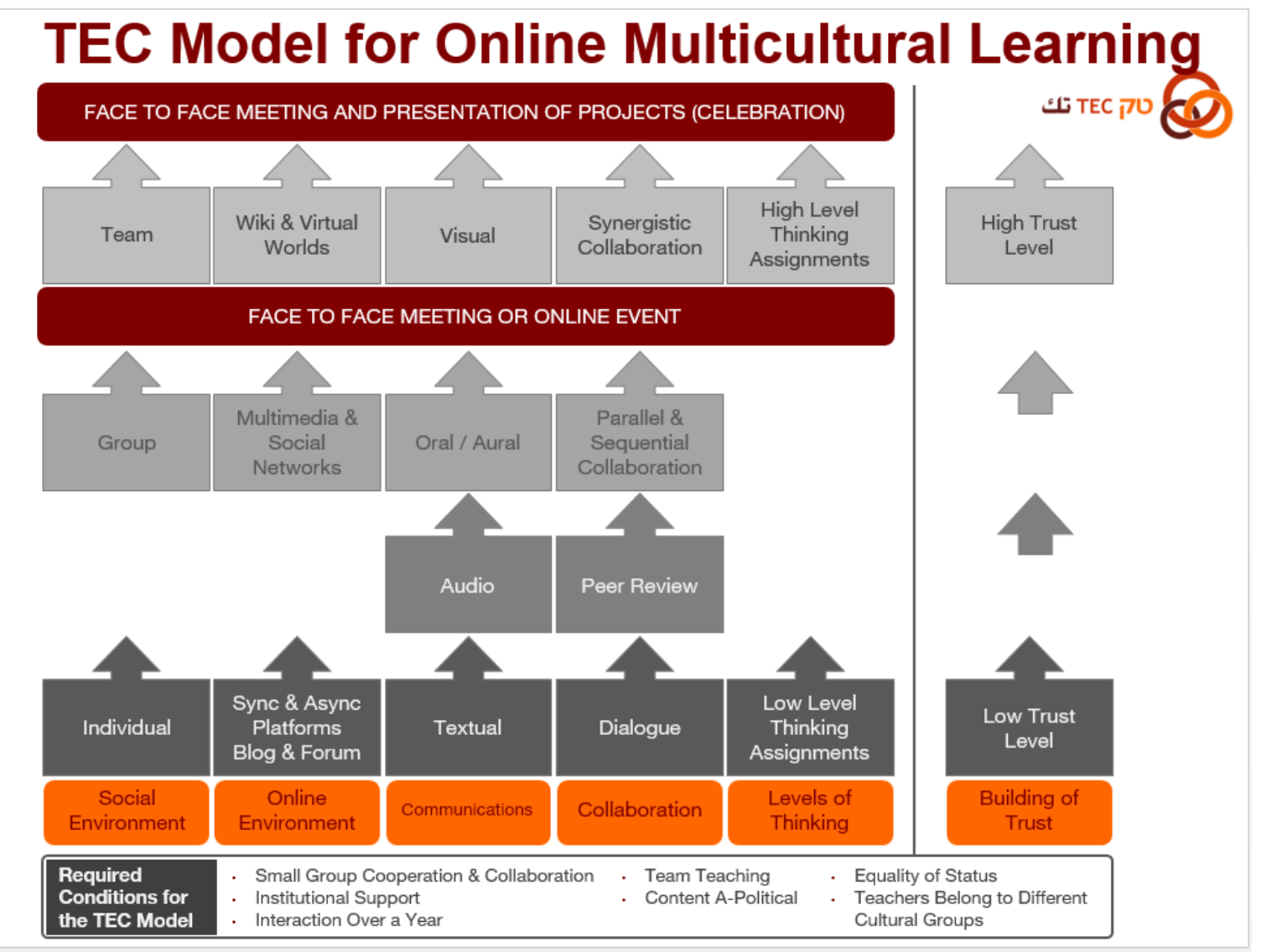

Figure 1. TEC model for online multicultural learning

The TEC model is based on the Pettigrew and Tropp (2000) model that expands the contact hypothesis (Allport, 1954). The contact hypothesis lays down the conditions for successful contact between two or more groups, to an online collaborative model. The contact hypothesis was developed by Allport to create effective intergroup interactions based on: (1) equal-status; (2) intergroup cooperation; (3) common goals; and (4) institutional/authority support. 
Pettigrew and Tropp (2000) refined their conditions and required that contact should be cooperative rather than competitive between partners of equal status, between groups rather than individuals, long-term rather than short-term, supported by the institution, and capable of leading to the development of a "super-ordinate identity"; that is, one that transcends local, regional, or national identity.

Face-to-face meetings provoke many logistical, political, and cultural barriers such as prejudice and stigmas. The Internet provided new opportunities for online interaction and meetings, and researchers began to examine the adaptation of the contact hypothesis to online rather than face to face since the mid-90s (Amichai-Hamburger \& McKenna, 2006; Hoter, Shonfeld, \& Ganayem, 2009).

A number of CMC projects have been carried out among diverse populations, specifically populations in conflict, based on the contact hypothesis. Probably the most documented one is the online project on Dissolving Boundaries, carried out from 1999 to 2008 between two different religious sectors, Northern Ireland and the Republic of Ireland (Austin \& Anderson, 2008). The Dissolving Boundaries project accompanied by research concluded that online communication has affected children's perceptions and prejudices.

In Israel, efforts to use CMC between Arab and Jewish populations have met with inconsistent results. Mollov and Lavie (2001) examined discussions that focused specifically on Jewish and Islamic religious practices through email exchanges between Israelis and Palestinians. They concluded that a one-to-one religious dialogue was a means for building Israeli-Palestinian understanding. However, group encounters that focused on political concerns did not result in reducing biases (Ellis \& MaOz, 2007).

The TEC model, based on Allports' principles, proposed a number of conditions in order to develop successful contact between learners from different cultures in conflict:

- Full support by each participating institution.

- Involve collaboration among groups rather than among individuals.

- Deal with non-conflicting issues (until building dialogue skills and trust between individuals).

- Be based on a need for participant collaboration rather than competition.

- Ensure participants have equal status.

- Progress gradually over a period of at least one year, with gradual use of communication technology; beginning with exchanges via the Internet followed by text and voice exchange and finally, after a positive online experience, by face-to-face encounters among the partners.

- Employ teachers who themselves come from the different cultural groups and who "team teach" the course in a collegial environment.

It adds the gradual development of contact between the groups by progressing from individual work to online synergetic collaborative work, and from asynchronous textual communication to synchronous audio communication and to the final stage of face-to-face communication.

\section{THE CONCEPTUAL FRAMEWORK OF THE STUDY}

TEC courses are identified as online collaboration teaching and learning in a multicultural environment. TEC courses are based on the TEC model developed by the TEC center, the Mofet Institute (Hoter et al., 2009), which reflects the online expansion of the contact hypothesis (Allport, 1954). Its aim is to build successful connections and trust building between groups in conflict.

TEC courses following the TEC model have been offered annually since 2005, and are designed for the diverse teacher education colleges in Israel. Participants, instructors and students, belong to different religions and cultural backgrounds, secular Jews, religious Jews and Arabs in Israel. Advanced Internet learning environments are used as the teaching and learning platforms.

This study is related to two of the TEC courses taking place in the 2016 academic school year (20152016): (1) an advanced learning environment course (SVIVOT), an interdisciplinary course (which 
focuses on computerized tools and online teaching methods including forums, blogs, wikis, film editing programs, and more); and (2) a TEC science disciplinary course (ECOLOGY).

Different subjects are taught online by the lecturers (instructors), and students are then required to work collaboratively in small-multicultural groups of six members each.

The courses are based on weekly interactions in synchronous and asynchronous online sessions. The Blackboard platform was used for the synchronous sessions every other week, and the Moodle LMS for asynchronous learning. Moodle was the main online environment of the course enabling students to interact at their convenience. This LMS includes learning materials, tasks, and discussion forums. A separate forum for each small multicultural group is opened for group discussions around their work on the tasks and anything else they decide to share with each other.

A team teaching approach from the three different cultures is used in all TEC courses. The instructors themselves work in a cooperative, non-competitive environment, representing the role model of a synergetic collaborative team for the students. Communication among the groups begins with the text-based forums, the lowest level of communication, and as the course progresses, the online communication develops to audio communication, and it keeps progressing for a few months until they meet face-to-face and reach oral communication.

Each participating teacher education college assigns an instructor and registers students for the different TEC courses. Students are then grouped into small culturally diverse groups within the TEC course, and each group is assigned one instructor who will accompany the group's interaction and work in an online setting throughout the academic year. Participants then work in small multicultural groups; each participant comes from a different college and a different culture, and the instructors become partners in the projects.

The tasks are relevant to teacher education and to student needs, and mostly require higher-level thinking skills. In each of the learning units, students receive a list of assignments necessitating the use of different technological tools and skills. To assess the students' work, a clear structured rubric for each assignment is developed. Examples of assigned tasks outputs include the development of an educational game and the creation of an educational video clip.

The tasks require different stages of collaboration and Higher Order Thinking Skills (HOTS), which are gradually developed along the course line. TEC courses emphasize developing ICT skills among students through exposure to new technological tools and requiring the implementation of those tools pedagogically in all course tasks.

At the end of the first academic semester or in the middle of the academic school year, students meet face-to-face in one of the participating colleges; they socialize, jointly develop a group product (such as logo, digital document, etc.), and submit it as a group task. At that point, the group's interests have become paramount and the cultural differences are transformed from threatening barriers to an enriching experience. Teamwork is part of the ideology and is modeled through team teaching by the culturally diverse course instructors.

The participants receive an individual as well as a group grade in which both cooperation and collaboration are taken into consideration. This is explained for each assignment in the rubric of the activity. Thus, participants understand the importance of collaborating and cooperating with their partners in order to achieve the maximum grade.

TEC courses develop various ICT and life skills: ICT skills, pedagogical use of ICT, collaboration, HOTS, and multicultural awareness.

The study focuses on the following research questions:

1. What is the level of ICT skills among TEC alumni?

2. How do the students perceive the role of TEC instructors in developing $21^{\text {st }}$ century skills: - Collaborative work 
- HOT (Higher Order Thinking)

- Pedagogical use of digital tools

- Multi-cultural awareness

3. What is the preferred learning style by the students: synchronous, asynchronous or F2F?

\section{METHODOLOGY}

The study was conducted using the descriptive quantitative method which gives an overall picture of the situation, and allows for examining the interrelations between relevant variables. A closed online survey was provided for the students of the TEC courses at the end of the academic year as an anonymous course feedback. The study compares several indices within the same school year. A detailed description of the research instrument is presented in the Instrument section.

Data was collected and evaluated for reliability by external research professionals, following a descriptive and comparative analysis conducted using the SPSS program. In addition, several relationships were studied as described in the results sections.

\section{PARTICIPANTS}

Students who participated in the TEC courses were in their final academic year towards a B.Ed. degree in the Teacher Education colleges. The TEC courses which participated in this study were Advanced Online Learning Environments (SVIVOT), and TEC Science course (ECOLOGY).

The aim of the TEC courses was to provide an online platform for collaboration among students from different cultures, in synchronous and asynchronous methods (mainly Blackboard and Moodle). In those courses, various online pedagogical tools were used (Padlet, Google Drive, Socrative, etc.). SVIVOT students learnt the educational use of the internet, integrating technology in the classroom, and planned a computerized lesson, while ECOLOGY students learnt the Ecology subject according to the TEC model.

The students were from different cultures and colleges: Jewish colleges (secular and religious) and Arab colleges (Table 1). They were majoring in different disciplines offered in their Colleges of Education, and their ages varied from high school graduates (18 years) to about 40 years old, more females than males.

Table 1. Research population - colleges and students

\begin{tabular}{|l|l|l|}
\hline College Name & Frequency & Valid Percent \\
\hline Beit Berl & 16 & 16.2 \\
\hline Alqasimi College & 16 & 16.2 \\
\hline Arab College Haifa & 11 & 11.1 \\
\hline Kay College & 9 & 9.1 \\
\hline Ohalo College & 24 & 24.2 \\
\hline Talpiot & 13 & 13.1 \\
\hline Kibbutzim & 9 & 9.1 \\
\hline Others & 1 & 1 \\
\hline Total & 99 & 100 \\
\hline
\end{tabular}


TEC courses are offered in the different colleges. Some colleges offer it as part of the elective course work, and others as part of the requirements towards earning the B.Ed. degree in different learning tracks (see Table 2). Students from each college were enrolled and distributed into different work groups in each of the TEC courses.

Table 2. Research population - students' learning track

\begin{tabular}{|l|l|l|}
\hline Educational Level & Frequency & Valid Percent \\
\hline Kindergarten & 5 & 5.1 \\
\hline Elementary & 35 & 35.4 \\
\hline Secondary & 43 & 43.4 \\
\hline Other & 16 & 16.2 \\
\hline Total & 99 & 100 \\
\hline
\end{tabular}

99 students participated in the study after completion of the academic year; $10 \%$ were male and $90 \%$ female. Teacher education colleges in Israel have a majority of females, where the school teaching profession is perceived as a female job. The Central Bureau of Statistics (CBS, 2017) shows that $81.4 \%$ of the teachers in Israel are female. $57.6 \%$ participated in the SVIVOT course, and $32.3 \%$ in ECOLOGY, while $10.1 \%$ of them participated in two courses.

The students reported that they studied in the following sectors: $35.4 \%$ Arabs, $44.4 \%$ general Jewish sector, $16.2 \%$ religious Jewish while they listed that they are affiliated with the following sectors: 55.6\% Jewish sector, 44.4\% Arabs (35.4\% Muslims, and 2\% Christians and 7\% Druze) (Table 3 and Table 4). About $53 \%$ of the participants have Hebrew as their mother tongue and $43 \%$ are Arabicspeakers, as can be seen in Table 5 .

Table 3. Research population: students' cultural sector

\begin{tabular}{|l|l|l|}
\hline Education Sector & Frequency & Valid Percent \\
\hline Religious Jewish & 16 & 16.2 \\
\hline General Jewish & 44 & 44.4 \\
\hline Arabic & 35 & 35.4 \\
\hline other & 4 & 4 \\
\hline Total & 99 & 100 \\
\hline
\end{tabular}

Table 4. Research population - students' religion

\begin{tabular}{|l|l|l|}
\hline Sectors & Frequency & Valid Percent \\
\hline Jewish & 55 & 55.6 \\
\hline Muslim & 35 & 35.4 \\
\hline Christian & 2 & 2 \\
\hline Druze & 7 & 7.1 \\
\hline Total & 99 & 100 \\
\hline
\end{tabular}


Table 5. Research population - student's mother tongue

\begin{tabular}{|l|l|l|}
\hline Mother tongue & Frequency & Valid Percent \\
\hline Hebrew & 52 & 52.5 \\
\hline Arabic & 43 & 43.4 \\
\hline English & 1 & 1 \\
\hline Others & 3 & 3 \\
\hline Total & 99 & 100 \\
\hline
\end{tabular}

\section{INSTRUMENTS}

This study is based on a closed questionnaire, which was developed by eight leading ICT instructors from eight different Teacher Education Colleges, and from different cultures. The survey is repeated each year in TEC courses, and instructors revise it according to previous experience and technological developments.

The survey was reviewed in two rounds: by TEC instructors and remarks were attended to and corrected, then a group of students not attending the courses were asked to fill out the questionnaire and take notes, and the instructors rewrote the questions according to the notes gathered. The instructors then took part in answering the questionnaire, took notes again, and worked together to correct the answers where needed. The content validity was found to be satisfying. The reliability (Alpha Cronbach) was calculated for each variable by its items, as listed in Table 6.

The research questionnaire consists of four major categories: ICT skills, instructor role in developing $21^{\text {st }}$ century skills, preferred learning communication style, and demographic questions:

Section I: ICT skills. Students were asked to rate their technological skills in using various online environments (portable devices, synchronous sessions, social network, collaborative tools, and virtual world); a new variable was calculated as the average of five items: using mobile communication, using social media, participating in synchronous sessions, participating in virtual reality environments, using collaborative tools (such as Google drive, Web 2.0). The items were rated on a scale from 1 to 5 .

Section II: Group instructor role in developing $21^{\text {st }}$ century skills among students in the following dimensions: collaboration work, HOT (Higher Order Thinking), pedagogical use of digital tools, and multicultural awareness. Students were asked to rate several items on a scale from 1 to 5.

Section III: Preferred learning communication style: Students were asked to mark their preferred learning method: F2f, blended learning and full distance online learning, and were then asked to rate their preferences regarding distance learning; asynchronous, synchronous and mixed (synchronous and asynchronous) methods.

Section IV: Background information demographic intermediate variables were added to identify the TEC course, group, gender, religious affiliation, majoring subject, college, language.

In addition, data was collected from the feedback given after each of the seven learning units. Students were asked to evaluate the unit via an online form using the Likert scale from 1 to 5 (Not at all - Slightly - Moderately -Very - Extremely).

Section V: Course evaluation: two additional variables were calculated from the course unit feedback: 
a) Group collaboration: This item was on a scale from 1 to 5 , reflecting the student's rate of his/her group collaboration in solving the unit task. Group collaboration rate was calculated as the average score of all group members' feedback.

b) Instructor support: This item was on a scale from 1 to 5 , reflecting the student's rate of their instructor support to his/her group while solving the unit task. Group instructor support was calculated as the average score of all the group members' feedback.

Table 6 indicates the reliability (Alpha Cronbach values) for the study variables:

Table 6. Reliability of the survey

\begin{tabular}{|l|l|l|}
\hline Dimension & $\begin{array}{l}\text { Reliability } \\
\text { (Alpha } \\
\text { Cronbach) }\end{array}$ & Items \\
\hline Collaboration work & 0.88 & $\begin{array}{l}\text { to lead students in online collaborative work } \\
\text { to instruct students to collaborate in a multicultural } \\
\text { environment } \\
\text { to develop collaborative work skills among students } \\
\text { to maintain a polite communication in the working } \\
\text { group } \\
\text { to solve problems among group members }\end{array}$ \\
\hline HOT & 0.89 & $\begin{array}{l}\text { to develop activities leading to thinking developing } \\
\text { to involve students in assessment } \\
\text { to arouse creative thinking in the workgroup } \\
\text { to challenge students with new topics }\end{array}$ \\
\hline $\begin{array}{l}\text { Pedagogical use of digital } \\
\text { tools }\end{array}$ & 0.82 & $\begin{array}{l}\text { to orient students with the different learning platforms } \\
\text { to teach students the use of different tools in digital } \\
\text { environments }\end{array}$ \\
\hline $\begin{array}{l}\text { Multicultural communica- } \\
\text { tion }\end{array}$ & 0.91 & $\begin{array}{l}\text { to interest students with new cultures } \\
\text { to instruct students to work in a multicultural environ- } \\
\text { ment }\end{array}$ \\
\hline
\end{tabular}

\section{RESULTS}

The findings relate to three major issues: (1) ICT skill level; (2) The role of the instructor in developing 21st century skills: a. Collaborative work; b. HOT; c. Pedagogical use of digital tools; d. Multicultural awareness; (3) Preferred learning styles: synchronous and asynchronous.

The following presents the study research questions followed by results:

\section{RQ1: What is the level of ICT skills among the students - TEC alumni?}

Most students reported high to extreme use of the ICT items on a scale from 1 to 5 , mainly the portable device with mean $=4.31$, and synchronized session with mean $=4.10$, and collaborative digital use with the mean $=4.02$.

$75 \%$ of the students considered themselves skillful in using ICT skills of mobile communication by reporting their levels "very" to "extreme". $70 \%$ reported themselves to be skillful in the use of social networks, about $73 \%$ for synchronized sessions, about $48 \%$ for the virtual world, and $73 \%$ for collaborative digital tools. 
A new calculated variable was created of the mean of all items; $(\mathrm{M}=3.99, \mathrm{SD}=0.81)$, which indicates that most students acquired a high level of ICT use, as described in Table 7.

Table 7. ICT skills analysis

\begin{tabular}{|c|c|c|c|c|c|c|}
\hline & $\mathrm{N}$ & Maximum & Mean & Std. Deviation & Variance & Kurtosis \\
\hline Portable devices & 99 & 5 & 4.31 & 0.98 & 0.97 & 2.52 \\
\hline Social networks & 99 & 5 & 3.97 & 1.07 & 1.15 & 0.07 \\
\hline Synchronized session & 99 & 5 & 4.1 & 0.92 & 0.84 & $0.71-$ \\
\hline Virtual world & 99 & 5 & 3.53 & 1.20 & 1.45 & $1.04-$ \\
\hline Collaborative digital tools & 99 & 5 & 4.02 & 1.02 & 1.04 & $0.20-$ \\
\hline *ICT skills (mean_q1) & 99 & 5 & 3.99 & 0.81 & 0.65 & $0.33-$ \\
\hline
\end{tabular}

RQ2: How students perceived the role of TEC instructors in developing $21^{\text {st }}$ century skills;

a. Collaborative work

b. HOT

c. Pedagogical use of digital tools

d. Multi-cultural awareness

Students rated the group instructor role in developing 21st century skills in four dimensions: collaboration work, HOT (Higher Order Thinking), pedagogical use of digital tools, multicultural communication. Students were asked to rate several items on a 1 to 5 scale, and reliability was then calculated for the subitems of each dimension, and only the items with high reliability were used in the calculation as listed below:

\section{A. GROUP COLLABORATION WORK}

This variable was measured as the mean of the following items, where Alpha Cronbach $=0.8$;

- to lead students in online collaborative work

- to instruct students to collaborate in a multicultural environment

- to develop collaborative work skills among students

- to maintain a polite communication in the working group

- to solve problems among group members

Examining the higher rated answers (degrees 4 and 5 on the Likert scale) results in a high contribution of the instructor in developing various $21^{\text {st }}$ century skills among TEC students. About $67 \%$ of students reported that the instructor should lead the group to collaborate in the group. $71 \%$ of the students preferred that the instructor train the students to collaborate in a multicultural environment. About $73 \%$ of the students reported their preference of the instructor to develop collaborative work skills among students within the group; $73 \%$ of them preferred that instructors develop online collaborative learning skills to ensure polite group communication; while $54 \%$ students reported that the instructor should solve group problems. Table 8 listed the percentage of high rated answers: 
Table 8. Group collaboration analysis

\begin{tabular}{|l|l|}
\hline Item & $\begin{array}{l}\text { Percentage of high rated answers } \\
(4+5)\end{array}$ \\
\hline To lead students in online collaborative work & 66.7 \\
\hline $\begin{array}{l}\text { To instruct students to collaborate in a multicultural environ- } \\
\text { ment }\end{array}$ & 71.7 \\
\hline To develop collaborative work skills among students & 72.8 \\
\hline To maintain a polite communication in the working group & 72.7 \\
\hline To solve problems among group members & 53.6 \\
\hline
\end{tabular}

The new variable "student perception of group instructor regarding group collaboration" is the mean of all items with $(\mathrm{M}=3.87, \mathrm{SD}=0.91)$, which indicates that most students prefer and expect an active role of the instructor to facilitate and develop the group work. Table 9 shows the statistics of the items used to measure the instructor role in collaboration.

Table 9. Instructor role analysis

\begin{tabular}{|l|l|l|l|l|l|l|}
\hline & N & & Mean & $\begin{array}{l}\text { Std. De- } \\
\text { viation }\end{array}$ & Minimum & Maximum \\
\hline Instructor role: Collaboration item & Valid & Missing & & & & \\
\hline $\begin{array}{l}\text { To lead students in online collaborative } \\
\text { work }\end{array}$ & 99 & 0 & 3.88 & 1.15 & 1 & 5 \\
\hline $\begin{array}{l}\text { To instruct students to collaborate in a } \\
\text { multicultural environment }\end{array}$ & 99 & 0 & 3.94 & 1.11 & 1 & 5 \\
\hline $\begin{array}{l}\text { To develop collaborative work skills } \\
\text { among students }\end{array}$ & 99 & 0 & 3.92 & 1.14 & 1 & 5 \\
\hline $\begin{array}{l}\text { To maintain a polite communication in the } \\
\text { working group }\end{array}$ & 99 & 0 & 4.03 & 0.96 & 1 & 5 \\
\hline To solve problems among group members & 99 & 0 & 3.58 & 1.18 & 1 & 5 \\
\hline $\begin{array}{l}\text { * Mean - student perception of group } \\
\text { instructor regarding group collaboration }\end{array}$ & $\mathbf{9 9}$ & $\mathbf{0}$ & $\mathbf{3 . 8 7}$ & $\mathbf{0 . 9 1}$ & $\mathbf{1}$ & $\mathbf{5}$ \\
\hline
\end{tabular}

Students were asked to rate their group collaboration after each task, the mean value of all group tasks was found to be 4.18 , $(\mathrm{SD}=0.42)$ which indicated high intergroup collaboration (see Table 10$)$. 
Table 10. Descriptive Statistics of Students evaluation of their group collaboration

(From Unit tasks feedback of group collaboration)

\begin{tabular}{|l|l|}
\hline Statistics & Value \\
\hline $\mathrm{N}$ & 99 \\
\hline Mean & 4.18 \\
\hline Median & 4.28 \\
\hline Std. Deviation & 0.42 \\
\hline Variance & 0.18 \\
\hline Range & 1.54 \\
\hline
\end{tabular}

Students rated the group instructor role (or support) in their group collaboration in the rate of 3.58 , in the students' task feedback (see Table 11).

Table 11. Students' evaluation of their group instructor support

\begin{tabular}{|l|l|}
\hline Statistics & Value \\
\hline $\mathrm{N}$ & 99 \\
\hline Mean & 3.58 \\
\hline Median & 3.62 \\
\hline Std. Deviation & 0.66 \\
\hline Variance & 0.43 \\
\hline Range & 2.44 \\
\hline
\end{tabular}

Significant correlation was found between the group collaboration factor and instructor support with spearman $r=.54(p<0.01)$ (see Table 12). This finding supports the earlier finding that students perceive the instructor role as a group facilitator in leading the group to work collaboratively and at the same time students reported that their groups worked collaboratively.

Table 12. Correlation between group collaboration and instructor support (based units' feedback)

\begin{tabular}{|l|l|l|l|}
\hline & & $\begin{array}{l}\text { From tasks feedback } \\
\text { of group collaboration }\end{array}$ & $\begin{array}{l}\text { Instructor } \\
\text { support }\end{array}$ \\
\hline $\begin{array}{l}\text { From tasks feedback of } \\
\text { group collaboration }\end{array}$ & Correlation Coefficient & 1 & $.539 * *$ \\
\hline & Sig. (2-tailed) & & 0 \\
\hline & N & 99 & 99 \\
\hline$* *$ Spearman's rho, Correlation is significant at the 0.01 level (2-tailed). \\
\hline
\end{tabular}

\section{B. HIGHER ORDER THINKING SKILLS AND INNOVATION}

This variable was measured as the mean of the following items, were Alpha Cronbach $=0.89$;

- to develop activities leading to thinking development 
- to involve students in assessment

- to arouse creative thinking in the workgroup

- to challenge students with new topics

About $67 \%$ of the students perceived that the instructor role (higher rated answers) in facilitating the group work should include developing activities leading student to develop thinking strategies; 69\% thought that the instructor role should emphasize and motivate creative thinking within the group; $70 \%$ reported that the instructor role is to involve the students in the assessment process; and $72 \%$ reported that instructor role is to challenge students with new subjects. Table 13 presents the percentage of high rated answers of the different HOT items:

Table 13. Instructor role in HOT

\begin{tabular}{|l|l|}
\hline Instructor role: Items for HOT & $\begin{array}{l}\text { Percentage for } \\
\text { high rated answers }\end{array}$ \\
\hline To develop activities leading to thinking developing & 66.7 \\
\hline To involve students in assessment & 69.7 \\
\hline To arouse creative thinking in the workgroup & 68.7 \\
\hline To challenge students with new topics & 71.8 \\
\hline
\end{tabular}

The new variable "higher order thinking skills and innovation" is the mean of all items with $(\mathrm{M}=$ 3.99, $\mathrm{SD}=0.89$ ), which indicates a higher students' rate of instructor contribution in this aspect, leading, motivating, and challenging the students through their collaborative work as presented in Table 14.

Table 14. HOT Analysis

\begin{tabular}{|l|l|l|l|l|l|l|}
\hline & $\mathrm{N}$ & Maximum & Mean & $\begin{array}{l}\text { Std. Devia- } \\
\text { tion }\end{array}$ & $\begin{array}{l}\text { Vari- } \\
\text { ance }\end{array}$ & Kurtosis \\
\hline & Statistic & Statistic & Statistic & Statistic & Statistic & Statistic \\
\hline $\begin{array}{l}\text { To develop activities leading to } \\
\text { thinking developing }\end{array}$ & 99 & 5 & 3.9 & 1.04 & 1.071 & $0.58-$ \\
\hline To involve students in assessment & 99 & 5 & 4.01 & 1.04 & 1.071 & $0.03-$ \\
\hline $\begin{array}{l}\text { To arouse creative thinking in the } \\
\text { workgroup }\end{array}$ & 99 & 5 & 3.96 & 1.05 & 1.1 & 0.20 \\
\hline $\begin{array}{l}\text { To challenge students with new } \\
\text { topics }\end{array}$ & 99 & 5 & 4.1 & 0.98 & 0.969 & $0.19-$ \\
\hline $\begin{array}{l}\text { *Mean - Higher order thinking } \\
\text { skills and innovation }\end{array}$ & $\mathbf{9 9}$ & $\mathbf{5}$ & $\mathbf{3 . 9 9}$ & $\mathbf{0 . 8 9}$ & $\mathbf{0 . 7 9}$ & $\mathbf{0 . 1 4 -}$ \\
\hline
\end{tabular}




\section{Pedagogical Use of Digital Tools}

This variable was calculated as the mean of the following two items (Alpha Cronbach $=0.82$ ):

- To orient students with the different learning platforms

- To teach students the use of different tools in digital environments

$58 \%$ of the students think that the instructor's role is to orient the students with the different learning platforms LMS, while $66 \%$ think that the instructor should teach the students suitable tools for the digital environments for pedagogical use. Table 15 presents the percentage of high rated answers:

Table 15. Instructor role in digital pedagogy

\begin{tabular}{|l|l|}
\hline Instructor role: Items for pedagogical use & $\begin{array}{l}\text { Percentage for high rated } \\
\text { answers }\end{array}$ \\
\hline To orient students with the different learning platforms & 57.6 \\
\hline To teach students the use of different tools in digital environments & 65.6 \\
\hline
\end{tabular}

The new variable "pedagogical use of digital tools" is the mean of the two items with $(M=3.73$, $\mathrm{SD}=1.03$ ), which indicates the students' perception of the instructor's role in teaching and training for pedagogical tools and environments. About $68 \%$ of the students highly rated this role, as can be seen in Table 16.

Table 16. Skills in digital pedagogy

\begin{tabular}{|l|l|l|l|l|l|l|}
\hline & $\mathrm{N}$ & Maximum & Mean & $\begin{array}{l}\text { Std. Devia- } \\
\text { tion }\end{array}$ & Variance & Kurtosis \\
\hline & Statistic & Statistic & Statistic & Statistic & Statistic & Statistic \\
\hline $\begin{array}{l}\text { To orient students with the different } \\
\text { learning platforms }\end{array}$ & 99 & 5 & 3.62 & 1.15 & 1.32 & $0.51-$ \\
\hline $\begin{array}{l}\text { To teach students the use of different } \\
\text { tools in digital environments }\end{array}$ & 99 & 5 & 3.84 & 1.10 & 1.2 & $0.53-$ \\
\hline $\begin{array}{l}* \text { Mean - Pedagogical use of digital } \\
\text { tools }\end{array}$ & $\mathbf{9 9}$ & $\mathbf{5}$ & $\mathbf{3 . 7 3}$ & $\mathbf{1 . 0 3}$ & $\mathbf{1 . 0 7}$ & $\mathbf{0 . 4 3 -}$ \\
\hline
\end{tabular}

\section{IMPROVING MULTICULTURAL AWARENESS}

This variable was calculated as the mean of the following two items (Alpha Cronbach $=0.91$ ):

- To interest students with new cultures

- To instruct students to work in a multicultural environment

$62 \%$ of the students think that the instructor's role is to interest students of new cultures and to voluntarily empower the multicultural awareness within the group, while $68 \%$ of the students think that the instructor should teach students to work in a multicultural environment. 
Table 17 shows the high rated answers:

Table 17. Instructor role in multicultural awareness

\begin{tabular}{|l|l|}
\hline Instructor role: multicultural awareness & Percentage for high rated answers \\
\hline To interest students with new cultures & 61.6 \\
\hline $\begin{array}{l}\text { To instruct students to work in a multicultural envi- } \\
\text { ronment }\end{array}$ & 67.7 \\
\hline
\end{tabular}

The new variable "improving multicultural awareness" is the mean of the two items with $(\mathrm{M}=3.82$, $\mathrm{SD}=1.1$ ), about $70 \%$ of the students rated highly the role of the instructor as leading multicultural awareness (see Table 18).

Table 18. Descriptive statistics of multicultural awareness

\begin{tabular}{|l|l|l|l|l|l|l|}
\hline & $\mathrm{N}$ & Maximum & Mean & $\begin{array}{l}\text { Std. Devia- } \\
\text { tion }\end{array}$ & Variance & Kurtosis \\
\hline Instructor role: cultural awareness & Statistic & Statistic & Statistic & Statistic & Statistic & Statistic \\
\hline To interest students with new cultures & 99 & 5 & 3.76 & 1.16 & 1.35 & $0.34-$ \\
\hline $\begin{array}{l}\text { To instruct students to work in a multi- } \\
\text { cultural environment }\end{array}$ & 99 & 5 & 3.89 & 1.13 & 1.28 & 0.16 \\
\hline $\begin{array}{l}\text { *Mean - Improving multicultural } \\
\text { awareness }\end{array}$ & $\mathbf{9 9}$ & $\mathbf{5}$ & $\mathbf{3 . 8 2}$ & $\mathbf{1 . 1 0}$ & $\mathbf{1 . 2 1}$ & $\mathbf{0 . 1 1}$ \\
\hline
\end{tabular}

RQ3: What is the preferred learning style for the students; Synchronous, asynchronous or $F 2 F$ ?

Students were asked to mark their preferred learning method in three different questions:

1. Preferred learning style among: F2F, blended learning, and full distance online learning

$45.45 \%$ preferred face to face method, and $43.43 \%$ preferred the blended method, while only $11.11 \%$ preferred fully online method (see Figure 2).

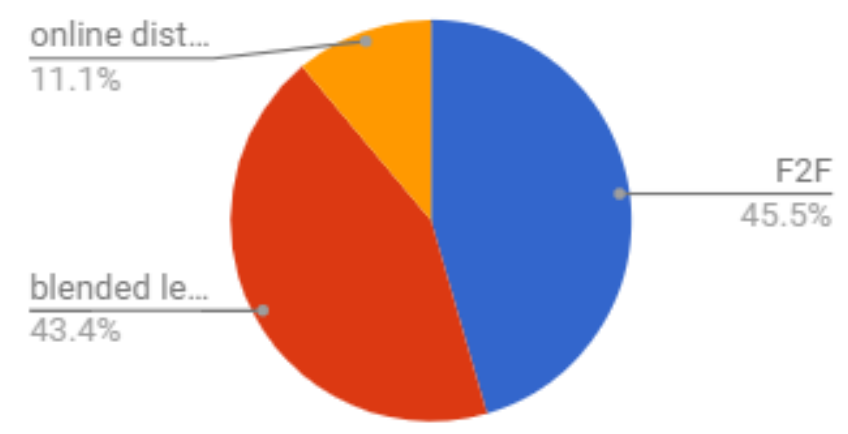

Figure 2. Preferred learning style 
2. Preferred online distance learning among: asynchronous, synchronous and mixed (synchronous and asynchronous)

Most of the students preferred the mixed method (59\%), a smaller number preferred the asynchronous style (29\%), and the rest preferred synchronous meetings, as can be seen in Figure 3:

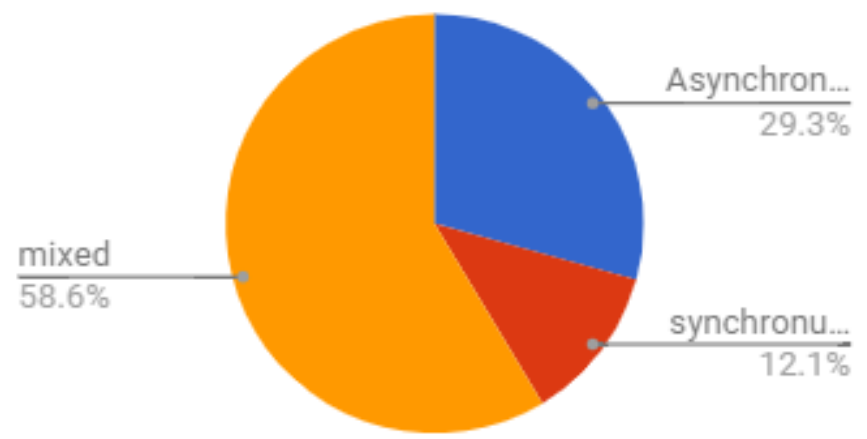

Figure 3. Preferred online learning style

3. On the scale of synchronous to asynchronous student's preference of learning style, students tended to prefer the asynchronous over the synchronous learning style, with the mean 3.58 on a scale of 1.synchronous to 5.asynchronous (see Figure 4).

\section{Synchronous and asynchronous On a scale}

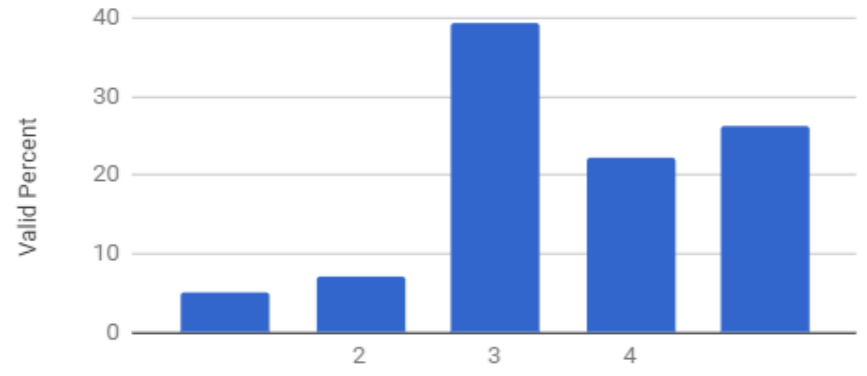

Figure 4. Synchronous and asynchronous on a preference scale

\section{DISCUSSION}

This study showed that TEC students were found to have high ICT skills, and high awareness of the need for developing $21^{\text {st }}$ century skills through instructors. It was also found that about half of the students still prefer the face to face learning style, and a blended online learning (of synchronous and asynchronous), with a tendency towards asynchronous meetings.

TEC courses have culturally diverse students, and the ICT skills may empower them in their life and as future teachers. Student ICT skills were highly ranked among students with $(M=3.99)$, and this indicates that most students acquire a high level of ICT skills through the course material, which is a major factor of the $21^{\text {st }}$ century skills defined as Information and media and technology skills.

Among the main goals in TEC center is to promote ICT skills and integrate them with pedagogical methods of teaching. Andrade (2016) and Goldstein and Asaf (2014) found this goal to be important in their research and the critical need to implement it in teacher training. TEC experience will give skilled graduating novice teachers confidence in life in general and empower their teaching skills in particular. 
On the other hand, we see from the results that more than $25 \%$ of TEC students have ranked their ICT skills below satisfaction level. This will reflect on the future school teachers who will rely mainly on their material knowledge rather than relying on ICT integrated pedagogy. The Ministry of Education policy has removed ICT lessons from the schools, and requested that ICT become integrated in the disciplinary lessons. Hence, a major challenge faces most of the schools, and mainly the teachers that lack those skills. Israel in particular has a high rate of Internet use, more than $90 \%$ of the youth are using the Internet in a very intensive way (ISOC-IL, 2017), and most Israeli students $(72 \%$ of the youth 13-18 years old) find the schools in Israel to be technologically dissatisfying. Goldstein and Asaf (2014) found that most of the pre-service teachers graduate with no practical experience in ICT integration in teaching. In most teacher education courses there were only basic forms of ICT integration while digital pedagogical models remained unpracticed. They concluded that the challenge today was the integration of ICT in education among college lecturers, school mentor teachers, and pre-service teachers. Voogt et al. (2017) also reported that teacher preparation for ICT-based teaching even in advanced countries is still insufficient to reach the goal of UNESCO (2009), which defined a teacher in the $21^{\text {st }}$ century as one who is skilled in building diverse learning environments for enrichment and management of teaching with ICT. Teacher training programs still seem to follow the model of traditional technology in education (Goldstein \& Asaf, 2014).

The use of pedagogical digital tools is an essential aspect in a teacher's career. TEC courses provide and train on various career skills that teachers need to acquire through their education and teaching practices, and which they will try to convey to their students through their courses. $68 \%$ of the TEC course students think that it is the instructor's role to promote the use of digital tools within the group work. Hence, the uniqueness of TEC courses in richness with advanced online teaching through various pedagogical models such as flipped classroom, synchronous and asynchronous strategies, small group collaboration etc. TEC courses accord with the studies of Jacobson-Lundenberg (2016) and Andrade (2016). Jacobson-Lundenberg showed how teaching $21^{\text {st }}$ century skills have modified the lives of college students and empowered them, despite the fact that those students came from a marginalized socio-economic community. Andrade (2016) showed how using ICT integrated pedagogy (flipped classroom) enhanced $21^{\text {st }}$ century skills among students.

Since ICT is part of our daily life, it is crucial to integrate ICT in education side by side with the development of other $21^{\text {st }}$ century skills. TEC courses not only teaches ICT skills in education, its model is designed to integrate gradually with various online pedagogical models that may give an answer to the need of developing $21^{\text {st }}$ century skills among teachers who will be more prepared to continue this process in schools with their pupils.

Despite the high ICT skills acquired by students and their successful experience in TEC courses (online distance learning), they do not prefer distance learning. In this study, we found that students in TEC courses complete their academic school year with a high level of ICT skills. About $43.43 \%$ of the participants still prefer face-to-face (F2F) learning communication style, $45.45 \%$ prefer the blended method, and $11.11 \%$ prefer full online learning. Of those preferring the online learning style, $59 \%$ preferred a mixed method of the synchronous and asynchronous methods, followed by $29 \%$ preferring the asynchronous method, and only $12 \%$ preferring the synchronous method. A study comparing learner satisfaction and learning outcomes in online and face-to-face learning environments with similar format, students in the face-to-face course held slightly more positive perceptions about the instructor and overall course quality than the online one (Johnson et al., 2000). Ganayem and Daher (2006) found that student's preference of learning style is based on five categories: emotional aspect, effectiveness, interaction, course type, and technological aspect. Garrison et al. (2001) emphasize in their model "community of inquiry" three essential elements: social presence, teaching presence, and cognitive presence. These elements enable the students to experience a unique and successful educational process. Salmon (2012) also emphasized the instructors' presence in a successful online learning. Various studies proposed the importance of designing rich activities to enable an appropriate interpersonal communication in online learning with the instructor and be- 
tween students (Faulkner et al., 2013, Harasim, 2017). It seems that the F2F learning style still has a higher social presence relative to online learning despite the high use of social media in our era, hence the need for developing more presence in online teaching and learning.

TEC instructors were found to be the facilitators for enhancing $21^{\text {st }}$ century skills among students in TEC courses. Student results were found to be prioritized as follow: Higher Order Thinking $(\mathrm{M}=3.99)$, online group collaboration $(\mathrm{M}=3.87)$, multicultural communication awareness $(\mathrm{M}=3.82)$, pedagogical use of digital tools $(\mathrm{M}=3.73)$. This complies with the Garrison model (Garrison et al. 2001), and OCL model of Harasim (2017) where the teacher's role shifted from being that of a provider/entertainer to being more of a facilitator as students took more responsibility for the learning process and for generating discourse. Students in TEC are required and encouraged to work collaboratively by the instructors through designing innovative online collaborative tasks.

Group collaboration is a critical factor for effective learning in the $21^{\text {st }}$ century. Despite the importance of the instructor's role in general and this skill in particular, it is also recommended to support and facilitate student responsibility in developing and leading their own group collaboration. The result of this study indicates that most student still think that the traditional role of instructor is to lead and facilitate group work. In order to enhance effective group collaboration, Stephens and Roberts (2017) proposed in their research the four phases of establishing group work, the FCOG strategy: (1) Creating groups; (2) Establishing expectations; (3) Communication tools; (4) Assignments and activities. In TEC courses all phases are taken into consideration, while the "establishing expectations" phase is not emphasized. We recommend revising this phase to ensure group collaboration effectiveness.

TEC students indicated that the instructors facilitated HOT activities in their learning process, most of the students (about two thirds) expect the instructor to challenge them with higher order thinking activities $(M=3.99)$. HOT is one of TEC model goals, and it is also emphasized by Harasim (2017), in addition to knowledge products that can be characterized as invention and innovation; new ideas, solutions, tools and technologies, as well as new applications of these inventions in new ways of doing things and of doing new things. Also in OCL classrooms, the teacher's role shifted from being that of a provider/entertainer to being more of a facilitator as students took more responsibility for the learning process and for generating discourse. Students' expectations meet OCL model that support high-level skills such as critical thinking, analytical thinking, synthesis, and evaluation.

One of the $21^{\text {st }}$ century skills is preparing the students for a diverse, multicultural global world. Multicultural communication and cooperation is much more productive in a rich ICT environment. TEC courses not only teach ICT skills in education, but also intend to enhance multicultural understanding and acceptance in an indirect way; through group collaborative work on an educational task. $70 \%$ of TEC students reported that they rate highly the role of the instructor as a multicultural facilitator in group work. Working collaboratively in small multicultural groups enables the participants to identify with the community in a trusting environment while developing inter-personal relationships (Garrison et al., 2001). TEC group identity based on Pettigrew and Tropp (2000) transcends local, regional, or national identity and emphasizes the small multicultural group work, according to the TEC model. Walter and his colleagues (2014) reported in the study that: (1) prejudice among Israeli Jews and Arabs declined in yearlong virtual teams; and (2) interpersonal factors correlate with better attitudes toward outgroups as a whole. It seems that working in small multicultural groups even without dealing with cultural and identity issues, can promote the awareness of other cultures. The TEC results meet the results of a similar project in Northern Ireland and the Republic of Ireland (Austin \& Anderson, 2008) and Arab Jewish online group work on Jewish and Islamic religious practices (Mollov \& Lavie, 2001). However, group encounters that focused on political concerns did not result in reducing biases (Ellis \& MaOz, 2007). Wach (2017) showed in her study the critical role of an intercultural online experience in broadening cultural knowledge and awareness. 
The contact hypothesis of Allport (1954) and its enhancement by Pettigrew and Tropp (2000) and later by the TEC model (Shonfeld et al., 2013) emphasize the issue of collaboration rather than competition. While the issue of the learning content is not sufficiently elaborated in those models, we think that the content should be carefully selected by an experienced multicultural team in a way that the content can enhance collaboration and gradually reflect cultural richness.

This study showed that the TEC model is appropriate to enhance $21^{\text {st }}$ century skills among learners, and the instructor has a critical role in leading the process.

\section{CONCLUSION}

In TEC courses, instructors succeeded in facilitating $21^{\text {st }}$ century skills among students such as ICT skills, online pedagogy, online collaboration, and multicultural awareness. Hence, it is worth widening TEC courses in all Teacher Education colleges in order to meet the expectations of the $21^{\text {st }}$ century teacher.

Online distance learning still lacks effective social presence, so it is essential to enrich those courses with a social presence in order to overcome the logistic and psychological obstacles of F2F meetings of distanced people (in location or in attitudes) and meet students preferences for face to face encounters. There is a need to deepen the study and implement new ideas to enhance the sense of presence of the instructors as well as advanced stages of collaboration among group members.

It is possible to enhance the TEC model by highlighting "group expectations" and by elaborating the issue of learning content in the context of cultural awareness. In addition, adding a qualitative aspect to the study may explore other added values and limitations of the TEC model as well as the expected skills by the participants.

\section{LIMITATIONS}

This study was based on a final survey among TEC students, although it might be more accurate to measure the $21^{\text {st }}$ century skills among the participants before and after participating in TEC courses in order to compare the results among the same research population. In addition, perception of $21^{\text {st }}$ century skills might be confused among the participants with their practical skills. In this case, it is possible to add an experimental part to the study before and after studies in TEC courses.

\section{REFERENCES}

Allen, I. E., \& Seaman, J. (2014). Grade change. Tracking online education in the United States. Babson Survey Research Group and Quahog Research Group. Retrieved from https://www.utc.edu/learn/pdfs/online/sloanc-report-2014.pdf

Allport, G. (1954). The nature of prejudice. Cambridge, MA: Perseus Books.

Amichai-Hamburger, Y. (2012). Reducing intergroup conflict in the digital age. In H. Giles (Ed.), The bandbook of intergroup communication (pp. 181-193). New York: Routledge.

Amichai-Hamburger, Y., \& McKenna, K. (2006). The contact hypothesis reconsidered: Interacting via the internet. Journal of Computer-Mediated Communication, 11(3), 825-843. https://doi.org/10.1111/j.10836101.2006.00037.x

Andrade, S. M. (2016). Curricular elements for learner success - 21 ${ }^{\text {st }}$ century skills. Journal of Education and Training Studies, 4(8), 143-149. https://doi.org/10.11114/jets.v4i8.1743

Austin, R., \& Anderson, J. (2008). Building bridges online: Issues of pedagogy and learning outcomes in intercultural education through citizenship, 4(1), 86-94. https://doi.org/10.4018/jicte.2008010108

Babacan, H. (2005). Challenges of inclusion: Cultural diversity, citizenship and engagement. Proceedings of International Conference on Engaging Communities, Brisbane, Australia, 1-18. Retrieved from https://researchonline.jcu.edu.au/17899/ 
Barkley, E., Cross, K., \& Major, C. (2014). Collaborative learning techniques: A bandbook for college faculty. John Wiley \& Sons.

CBS (Central Bureau of Statistics). (2017). Teaching staff in schools by level of education and selected characteristics. Retrieved from http://www.cbs.gov.il/shnaton68/st08 33.pdf

Ellis, G. D., \& Maoz, I. (2007). Online argument between Israeli Jews and Palestinians. Human Communication Research, 33(3), 291-309. https://doi.org/10.1111/j.1468-2958.2007.00300.x

Faulkner, P., Doamekpor, P., \& Yeboah, O. (2013). Peer groups and pairs: many benefits for the online setting. NaCTA Journal, 57(4), 80.

Ganayem, A., \& Daher, W. (2006). Synchronous and asynchronous teaching and learning: aspects affecting preferences of preservice teacher. Presentation at the Virtual Conference on Opening Gates in Teacher Education: In the Face of the Challenges of Education and Teaching, Mofet Institute, Tel Aviv, Israel.

Garrison, D., Anderson, T., \& Archer, W. (2001). Critical inquiry in a text-based environment: Computer conferencing in higher education. The Internet and Higher Education, 2, 87-105. https://doi.org/10.1016/S1096-7516(00)00016-6

Ghanem, A. (2001). The Palestinian-Arab minority in Israel, 1948-2000: A political study. Albany, NY: SUNY Press.

Goldstein, O. \& Asaf, M. (2014). Evaluation of pre-service teachers' preparation for ICT teaching in Israeli colleges of education. In J. Viteli \& M. Leikomaa (Eds.), Proceedings of EdMedia: World Conference on Educational Media and Technology 2014 (pp. 131-140). Waynesville, NC: AACE. Retrieved from http://www.editlib.org/d/147493

Goldstein, O., \& Tesler, B. (2017). The impact of the national program to integrate ICT in teaching in preservice teacher training. Interdisciplinary Journal of E-Skills and Lifelong Learning, 13, 151-166. https://doi.org/10.28945/3876

Harasim, L. (2017). Learning theory and online technologies. Abingdon, UK: Taylor \& Francis.

Hartman, J., Dziuban, C., \& Moskal, P. (2000). Faculty satisfaction in ALNs: A dependent or independent variable? Journal of Asynchronous Learning Networks, 4(3), 155-179.

Hoter, E., Shonfeld, M., \& Ganayem, A. (2009). ICT in the service of multiculturalism. The International Review of Research in Open and Distance Learning, 10(2). Retrieved from http://www.irrodl.org/index.php/irrodl/article/view/601/1207

ISOC-IL (Israel Internet Association). (2017). The Israeli Surfer: Gaps in internet use in Israel between Jews and Arabs.

Israeli Ministry of Education. (2011). Transforming the education system to match the demands of the 21st century: The national plan [Hebrew]. Jerusalem. Retrieved from http://cms.education.gov.il/NR/rdonlyres/79B5A8CFF812-4A63-89BE-3BE-FEB887EC5/142454/12.pdf

Jacobson-Lundeberg, V. (2016). Pedagogical implementation of 21st century skills. Educational Leadership and Administration, 27(March), 82-100.

Johnson, S., Aragon, S., Shaik, N., \& Palma-Rivas, P. (2000). Comparative analysis of learner satisfaction and learning outcomes in online and face-to-face learning environments. Journal of Interactive Learning Research, 11(2), 29-49. Retrieved from

https://search.proquest.com/openview/4fa03dae1dfd9155526ac093fdfcaafa/1?pqorigsite $=$ gscholar\&cbl $=2031153$

Mollov, B., \& Lavie, C. (2001). Culture, dialogue, and perception change in the Israeli-Palestinian conflict. The International Journal of Conflict Management, 12(1), 69-87. https://doi.org/10.1108/eb022850

Online Learning Consortium. (2015). Online report card - Tracking online education in the United States. Retrieved from https://onlinelearningconsortium.org/read/online-report-card-tracking-online-education-unitedstates-2015/

P21 (Partnership for 21st Century Learning). (2015). P21 Framework definitions. Washington, DC. Retrieved from http://www.p21.org/our-work/p21-framework

Pettigrew, T., \& Tropp, L. (2000). Does intergroup contact reduce prejudice? Recent meta-analytic findings. In S. Oskamp (Ed.), Reducing prejudice and discrimination (pp. 93-114). Mahwah, NJ : Erlbaum. 
Roberts, G. (2003). Teaching using the web: Conceptions and approaches from a phenomenographic perspective. Instructional Science, 31, 127-150. https://doi.org/10.1023/A:1022547619474

Salmon, G. (2012). E-moderating: The key to online teaching and learning. Innovations in Education and Teaching International, 49 (2): 233-234. https://doi.org/10.1080/14703297.2012.678665

Shonfeld , M., Hoter, E., \& Ganayem, A. (2013). Improving collaborative online learning using the TEC model. In M. S. R. McBride \& \& M. Searson (Eds.), Proceedings of Society for Information Technology \& Teacher Education International Conference (pp. 1028-1033). New Orleans, LA: Association for the Advancement of Computing in Education (AACE). Retrieved July 14, 2018 from https://www.learntechlib.org/primary/p/48252/.

Stephens, G. E. \& Roberts, K. L. (2017). Facilitating collaboration in online groups. Journal of Educators Online, 14(1). https://www.thejeo.com/archive/archive/2017 141/jeo facilitating collaboration in online groupspdf

Viceblai, E. (2013). The Israeli educational system: Key issues discussed by the education committee [Hebrew]. Jerusalem, Israel. Retrieved from http://www.knesset.gov.il/mmm/data/pdf/m03160.pdf

Voogt, J., Valtonen, T., Sointu, E., Kontkanen, S., Kukkonen, J., Pöntinen, S., . . Rosenberg, J. (2017). (Future) Teachers' use of technology and development of TPACK: Insights from a global perspective. In P. Resta , \& S. Smith (Eds.), Proceedings of Society for Information Technology \& Teacher Education International Conference 2017 (pp. 2499-2502). Austin, TX, United States: AACE. Retrieved from https://www.learntechlib.org/p/177951/

Wach, A. (2017). Intercultural experience in online collaboration: A case of Polish and Romanian teachertrainees. The Electronic Journal for English as a Second Language, 20(4), 1-22. Retrieved from http://www.teslej.org/wordpress/issues/volume20/ej80/ej80a3/

Walther, J., \& Bunz, U. (2005). The rules of virtual groups: Trust, liking, and performance in computermediated communication. Journal of Communication, 55(4), 828-846. https://doi.org/10.1111/j.14602466.2005.tb03025.x

Walther, J., Hoter, E., Ganayem, A., \& Shonfeld, M. (2015). Computer-mediated communication and the reduction of prejudice: A controlled longitudinal field experiment among Jews and Arabs in Israel. Computers in Human Behavior, 550-558. https://doi.org/10.1016/j.chb.2014.08.004

\section{BIOGRAPHIES}

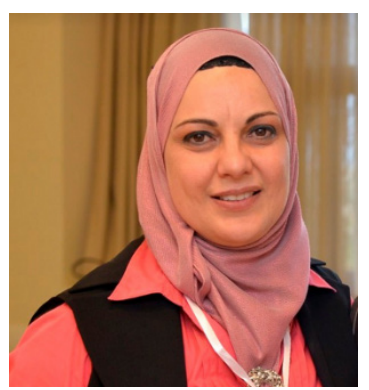

Asmaa Ganayem is the first researcher on Internet usage and the digital gap in Arab society in Israel, technology entrepreneur, expert on the development and assimilation of innovative pedagogical models in teaching and learning. Co-founder and co-director of the TEC Center at the MOFET Institute, and lecturer at Al-Qasemi Academic College of Education. She was chosen as Woman of the Year on the Internet by surfers in the Arab sector in 2011 and 2016. She completed her MA in Information Systems in Berlin, and her PhD in Internet Research at the University of Haifa

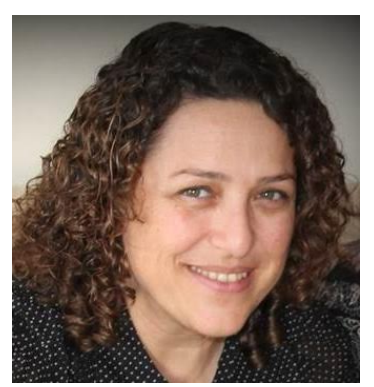

Wafa Zidan is a Lecturer in the Arab Academic College of Education in Haifa. A pedagogical trainer, instructor, and a researcher in the field of online teaching, educational technology, and distance learning courses in the college. She developed a course and teaches it for early childhood caregivers; on how to utilize technology in early childhood. Ms. Zidan is a team member of the TEC (Technology, Education and Cultural diversity) center in the Mofet Institute, which develops, researches and implements technological projects in multicultural settings among Arabic and Hebrew speaking schools. She is also part of the Professional development team for School Teachers. 